\title{
Mecanismos de defensa en plantas. Proteínas relacionadas con la patogenicidad
}

\author{
Defense mechanisms in plants. Proteins related to pathogenicity \\ Eduardo Menéndez $\square$, (D) Julio Navarro, (D) Jorge López, (D) Augusto Dalmau
}

Universidad Le Cordon Bleu. Lima, Perú

Recibido: 01/09/2020 Revisado: 25/10/2020 Aceptado: 23/11/2020 Publicado: 16/12/2020

\section{RESUMEN}

Desde sus orígenes, las plantas terrestres vasculares han coexistido con una amplia variedad de bacterias y hongos. Con la aparición de los insectos, de igual forma mantuvieron una estrecha relación con estos, tomando un carácter especial con la llegada de las plantas con flores en el período Cretácico temprano. Los diferentes procesos evolutivos han propiciado el desarrollo de una serie de relaciones interespecíficas, algunas de ellas beneficiosas para ambas partes como pudieran ser los variados mecanismos de polinización por medio de insectos en muchas especies de plantas y al mismo tiempo han surgido otros tipos de interacciones con especies capaces de producir enfermedades serias en las diferentes partes de las plantas. Esta presión de selección, unido a la imposibilidad de defensa que ofrece la locomoción, así como la carencia de un sistema de defensa basado en anticuerpos, han sido las principales responsables de la aparición en las plantas de complejos mecanismos de defensa, muchas veces rápidos y eficaces frente a las especies agresoras y otras veces no. La manifestación de las patologías en las plantas depende de complejas interacciones entre el huésped y el patógeno, lo que es un indicador de su evolución conjunta. De aquí la exquisita regulación de los mecanismos de agresión/defensa y la correspondiente selectividad en el reconocimiento de agentes agresores externos, lo que puede explicar la diferente sensibilidad de distintas especies o incluso diferentes variedades dentro de la misma especie. Desde hace un tiempo a la fecha, los investigadores han mostrado mucho interés en ciertas proteínas sintetizadas por la planta cuando es atacada por un microorganismo patógeno. Dado que aparecen en condiciones patológicas, han sido nombradas proteínas relacionadas con la patogenicidad o PR. Palabras clave: proteínas PR, mecanismo de defensa, Proteínas PR-3 y proteínas PR-5.

\section{ABSTRACT}

Since their origins, vascular land plants have coexisted with a wide variety of bacteria and fungi. When insects appeared, they also maintained a close relationship with them, taking on a big role with the arrival of flowering plants in the early Cretaceous period. The different evolutionary processes have led to the development of a series of interspecific interactions; 
some of them beneficial for both parties, such as the various pollination mechanisms through insects in many plant species. At the same time, other types of interactions have emerged with species capable of producing severe diseases in different sections of the plant. This evolutionary pressure with the inability of a defense offered by locomotion, and the lack of a defense system based on antibodies, have been the main responsible for the appearance of complex defense mechanisms in plants, many times rapid and effective against aggressive species, and sometimes not. The pathologies manifestation in plants depends on complex interactions between host-pathogen, which is an indicator of joint evolution. Thus, the exquisite regulation of aggression/defense mechanisms and the corresponding selectivity recognizing external aggressors, may explain the distinct sensitivity of various species or even different varieties within the same species. For some time now, researchers have shown great interest in certain proteins synthesized by a plant when attacked by a pathogenic microorganism. Since they appear in pathological conditions, they have been named Pathogenesis-related (PR) proteins. Keywords: PR proteins, defense mechanism, PR-3 proteins and PR-5 proteins.

\section{INTRODUCCIÓN}

En las plantas se distinguen dos modos de respuesta generalizada frente a un patógeno. La primera consiste en una reacción hipersensible en la que se produce una necrotización local en la zona del tejido infestado, aislando así al patógeno e impidiendo su multiplicación y propagación Este suele ser el caso frente a algunos virus y hongos patógenos. El segundo modo consiste en una reacción sistémica en la que la respuesta se produce a lo largo de todos los tejidos de la planta independientemente de si están infectados o no. En cualquiera de los dos modos de respuesta, resulta evidente que deben existir mecanismos específicos de señalización y transducción de señales entre la planta y el patógeno (Lamb et al., 1989).

El establecimiento de la infección por parte de un micro-organismo suele implicar, la ocurrencia de sucesos como: la adhesión a la superficie de la planta, la degradación de componentes de la pared celular, la formación de estructuras de penetración y la producción de toxinas en el caso de los hongos (Lamb et al., 1989). La liberación de fragmentos de la pared celular, tanto de los hongos patógenos, como de la propia planta, por medio de la acción de enzimas hidrolíticas como la $\beta$-1,3-glucanasa o la quitinasa del agente agresor y (o) el huésped, actúan como señales inductoras del desencadenamiento de los sucesos que constituyen la respuesta de defensa (Ryan, 1987; Takeuchi et al., 1990; Ham et al., 1991).

Una vez que la planta identifica la presencia de un patógeno, se produce una transducción de señales que activará el mecanismo defensivo. Puesto que las infecciones comienzan usualmente por el apoplasto, la interiorización de la señal patogénica deberá ser mediada a través de la membrana plasmática. De hecho, se ha descrito que la infección de plantas por hongos o la exposición de las mismas a elicitores fúngicos, origina cambios rápidos en el potencial de membrana y en el transporte de protones, que en buena medida pueden venir mediados por la modulación de la actividad de la ATPasa de la membrana plasmática (Mayer y Ziegler, 1988). También está descrito que el ión $\mathrm{Ca}^{+2}$ puede jugar un importante papel en la interiorización de la señal patogénica, así como las variaciones en los niveles de inositol trifosfato y en la acción de enzimas del tipo kinasas y desfosforilasas (Dixon y Lamb, 1990). La transducción de señales 
no se limita a la célula afectada por el patógeno, también se establecen señales defensivas a lo largo de los tejidos afectados, de los adyacentes e incluso en la planta entera.

Compuestos como el etileno y el ácido absícico, el ácido salicílico o el metil-jasmonato, son considerados mediadores de la inducción de diferentes genes de defensa de la planta $(\mathrm{Bu}-$ chel y Linthorst, 1999; Velazhan et al., 1999).

Los genes que codifican las distintas proteínas relacionadas con fenómenos defensivos y adaptativos ante diversas situaciones patogénicas y de estrés, pueden clasificarse dentro de los tres grupos que se describen a continuación:

1. Genes que codifican proteínas implicadas en el reforzamiento y reparación de la pared celular.

2. Genes que codifican proteínas con una misión claramente defensiva, por ser antimicrobianas o por participar en la síntesis de compuestos antimicrobianos. Ej: los inhibidores de proteasas, lectinas y permeabilizadores de membrana, hidrolasas y peroxidasas.

3. Genes que codifican proteínas del metabolismo secundario de la planta, cuya expresión se induce en presencia del patógeno y que intervienen en la ruta de los fenil-propanoides. Estas enzimas intervienen en la formación de metabolitos secundarios como alcaloides, fitoalexinas, flavonoides, pigmentos, lignina $\mathrm{y}$ otros compuestos con funciones protectoras.

\section{DESARROLLO}

\section{Proteínas Relacionadas con la Patogénesis (Proteínas PR)}

A principios de la década de los setenta, se observó que diferentes variedades de tabaco resistentes a la infección con TMV acumulaban una serie de proteínas tras la reacción hipersensible originada (Gianinazzi et al., 1970; Van Loon y Van Kammen, 1970). Mas tarde se descubrió que estas proteínas también se acumulaban en otras especies e incluso se demostró su inducción por otros patógenos o por exposición a ciertos agentes químicos (Kauffmann et al., 1987; Legrand et al., 1987; Nasser et al., 1988). Antoniw et al. (1980) propusieron que estas proteínas se denominaran proteínas relacionadas con la patogénesis o proteínas PR. Desde entonces, la gran cantidad de nuevas proteínas descritas en situaciones de estrés en numerosas especies monocotiledóneas y dicotiledóneas han creado una gran confusión tanto en la definición y nomenclatura del grupo (Cutt y Klessig, 1992).

Para hacer frente a los problemas que planteaba la ausencia de criterios clasificadores, se creó la comisión para la nomenclatura de estas proteínas durante el Segundo Taller sobre "Pathogenesis-Related Proteins" celebrado en 1989 en Valencia, España. Desde entonces las proteínas PR están definidas como proteínas inducidas en situaciones patológicas o análogas (Van Loon, 1999). Se entiende por situaciones patológicas en las plantas tanto las reacciones hipersensibles como las heridas provocadas por ataques parasíticos por nemátodos, insectos y animales herbívoros. Las situaciones análogas incluyen las causadas por la aplicación de agentes químicos tales como: elicitores y ácido salicílico que inducen algunos aspectos de la respuesta del huésped (Leubner-Metzger et al., 1998; Kuwabara et al., 1999), al igual que respuestas a la fractura mecánica que conllevan un cúmulo de la misma clase de proteínas que son inducidas por las infecciones. Van Loon et al. (1987) y Bol y Van Kan (1988) propusieron la clasificación de las proteínas 
PR de tabaco en cinco grandes grupos, basándose en su funcionabilidad y (o) reacción inmunoserológica. El primer grupo comprende a las llamadas proteínas PR-1, de masas moleculares cercanas a $14 \mathrm{KDa}$, y su función es por el momento desconocida, aunque hay algunas evidencias de su poder antifúngico, tiene altos niveles de expresión. Al grupo de las proteínas PR-2 pertenecen las $\beta$-1,3-glucanasas enzimas que serán tratadas de forma particular en este trabajo. El tercer grupo reúne a las proteínas PR-3, enzimas con actividad quitinasa cuyo papel en los mecanismos de defensa contra los hongos está muy ligado a las $\beta$-1,3-glucanasas. El cuarto grupo es un tanto especulativo; está formado por proteínas PR-4 de masa molecular aproximada a 15 KDa y cuyas funciones aún son desconocidas. Por último, un quinto grupo está constituido por una serie de proteínas (PR-5) de masa molecular cercana a $23 \mathrm{KDa}$ y de secuencias aminoacídicas homólogas a la taumatina.

Basándose en esta clasificación, Van Loon et al. (1994) han propuesto una serie de normas y recomendaciones para nombrar a cada una de las proteínas PR de distintas especies con el fin de establecer un consenso en su nomenclatura. En primer lugar indicaría el grupo en el que está incluida la proteína; En segundo lugar y en letras minúsculas se indicaría la proteína en particular dentro del grupo y por último, en números romanos y entre paréntesis, se señalaría la clase de enzima dentro del grupo: Por ejemplo, la PR-2A (II) de tomate sería una $\beta$-1,3-glucanasa de la clase II.

Las proteínas PR se sintetizan como respuesta a una serie de patógenos como hongos, bacterias, virus o viroides e incluso a moléculas elicitoras derivadas de la pared del hongo o la bacteria (Ryan, 1990). Pero también se sintetizan por la acción de ciertos compues- tos químicos como la plata (Conejero, 1981; Conejero y Granell, 1986), los ácidos salicílicos, acetilsalicílico y benzoico (White, 1979), el quitosan (producto soluble derivado de la quitina) y el ozono (Ernest et al., 1992).

Existen evidencias de que algunos genes de proteínas PR se expresan en situaciones normales del desarrollo de la planta, relacionándolos con funciones no patológicas (Felix y Meins, 1986; Castresana et al., 1990; De Jong et al., 1992; Vogeli-Lage et al., 1994). Por otro lado, existen datos acerca de que la presencia wde proteínas PR también se ve afectada por los niveles endógenos de los reguladores del crecimiento auxinas y citoquininas (Carr y Klessig, 1989). La modificación del balance de estos dos tipos de reguladores, asociados al desarrollo y mantenimiento de los estados de diferenciación, pueden ser la causa de la presencia de proteínas PR en plantas sanas. El etileno es muy importante por su implicación como inductor natural en la ruta de la señal de transducción (Conejero et al., 1990). El etileno parece inducir en mayor grado la expresión de las proteínas PR de carácter básico en tabaco (Velazhan et al., 1999). El ácido salicílico está implicado en el desarrollo de la reacción sistémica inducida en hojas no infectadas, debido a que su aplicación exógena produce la inducción de algunas de las proteínas PR (White, 1979).

Algunas proteínas PR están presentes solo en los órganos florales (Lotan et al., 1989; Neale et al., 1990; Beerhues y Kombrink, 1994; Delp y Palva, 1999), lo que demuestra una elevada especificidad por un tipo de tejido, al localizarse en los pistilos, en los sépalos o en el ovario. En las plantas de tabaco, el desarrollo floral coincide con la senescencia de las hojas inferiores y la acumulación de proteínas PR ácidas en las flores puede ser in- 
hibida por la escisión de las hojas inferiores. Las proteínas PR básicas de tabaco se han localizado en las hojas inferiores, así como en raíces de plantas sanas (Felix y Meins, 1986). Todo esto sugiere la existencia de múltiples señales coordinadoras del desarrollo.

Los trabajos en los últimos años han estado dirigidos al aislamiento de los genes de muchas proteínas PR, así como a la elucidación de la estructura de alguno de sus promotores. Una de las primeras conclusiones que se han obtenido es que los genes PR están regulados a nivel de la transcripción, ocurriendo la acumulación del ARN mensajero de forma paralela a la de la proteína correspondiente (Castresana et al., 1990). Otro resultado notable de estos estudios ha sido el descubrimiento de las cajas reguladoras en los promotores; en algunos casos se han reconocido los elementos del promotor necesarios para la inducibilidad por ácido salicílico o por TMV, aunque algunos de los datos obtenidos por distintos grupos de investigadores parecen contradictorios, como es el caso de la PR-1a de tabaco (Cutt y Klessig, 1992).

\section{Proteínas PR-3}

La implicación de $\beta$-1,3-glucanasas (EC 3.2.1.39) en la defensa activa de las plantas ante los ataques de patógenos, se propuso antes de su clasificación como grupo de proteínas PR-2 (Abeles et al., 1971). Estas proteínas representan un grupo de enzimas capaces de hidrolízar los $\beta$-1,3-glucanos presentes en la pared celular de hongos (Keen y Yoshikawa, 1983; Ham et al., 1991) y que cuando actúan de forma sinérgica junto a otras enzimas hidrolíticas como las quitinasas, se potencian las posibilidades de causar daños a la pared de los hongos (Mauch et al., 1988; Takeuchi et al., 1990; Sela- Buurlage et al., 1993). Se ha demostrado, mediante ensayos in vitro, que estos dos grupos de enzimas son capa- ces de inhibir la esporulación y (o) germinación de los hongos en cultivo líquidos, aunque esta inhibición ha resultado ser en algunos casos transitoria (Ludwing y Boller, 1990).

Algunas $\beta$-1,3-glucanasas están reguladas por los niveles de fitohormonas durante el proceso de desarrollo (Cote et al., 1991 y Delp y Pava, 1999), aunque su papel en plantas sanas no está totalmente establecido. Por su distribución en las plantas y sus sustratos, se les ha atribuido diferentes papeles relacionados con la maduración del fruto (Hinton y Pressey, 1980), con el crecimiento del tubo polínico (Ori et al., 1990), con la regulación del transporte de los tejidos vasculares, (Clarke y Stone, 1962), con la biosíntesis de celulosa (Meier et al., 1981), con la división celular (Fulcher et al., 1976), con el desarrollo de microsporas, (Worral et al., 1992) y con la germinación de semillas de plantas dicotiledóneas (Vogeli-lange et al., 1994). De hecho, la comprensión del papel de estas enzimas en la respuesta a la enfermedad, y durante el desarrollo natural de la planta, es muy complicada, si tenemos en cuenta que esta actividad enzimática está producida por varias isoformas que difieren entre sí en la secuencia aminoácida, en la localización celular y en la inducibilidad.

Las $\beta$-1,3-glucanasas son ampliamente estudiadas en diferentes especies vegetales (Vogeli et al., 1988; Beffa y Meins, 1997), destacándose por su amplitud y variedad los trabajos realizados en tabaco (Meins et al., 1992). Según la similitud de su secuencia, las $\beta$-1,3-glucanasas del tabaco fueron clasificadas en tres grupos estructurales: la clase I, que incluye por lo menos tres isoformas básicas que se caracterizan por la presencia de una extensión C-terminal llamada propéptido, necesario para su localización en vacuolas, la clase II, formada por isoformas ácidas que se acumu- 
lan principalmente en el apoplasto, y por último, la clase III, de la cual sólo se conoce una isoforma ácida, supuestamente localizada en el apoplasto (Payne et al., 1990). Las tres clases poseen entre sí una homología global aproximadamente de un $50 \%$, siendo esta homología predominante en los dominios catalíticos.

Las enzimas glucanasas forman una extensa familia. En la actualidad existen asilados de nuevas isoformas que aún no han sido incluidas en esta clasificación. Una de estas isoformas guarda relación serológica con la clase I, aunque posee propiedades diferentes: se encuentra en flores de plantas sanas y está glicosilada (Lotan et al., 1989). En Nicotiana plumbaginifolia se ha aislado un gen gnl, de una $\beta$-1,3-glucanasa básica e intracelular (Castresana et al., 1990). Posee alrededor de un $60 \%$ de homología con la clase I de tabaco y un $70 \%$ con la clase II. Su grado de expresión es menor que el resto de las isoformas, razón por la que quizás no se ha detectado en tabaco. Además de estar presente en plantas sanas (en la raíz y en menor grado en las hojas inferiores), se expresa alrededor de las zonas necrosadas en las reacciones hipersensibles. La expresión del gen gn1 está fuertemente inducida por el ácido salicílico y débilmente por el etileno (Leubner-Metzger et al., 1998).

En una misma planta hay gran cantidad de genes codificadores con actividad $\beta$-1,3-glucanasas (Leubner-Metzger y Frederick, 1999). De la observación de esta variedad de isoformas se pudiera entender la importancia que para una planta presupone este tipo de actividad hidrolítica. En cuanto a la defensa de las plantas, los supuestos mecanismos de acción de las $\beta$-1,3-glucanasas fueron postulados en función de su capacidad individual de inhibición del crecimiento de hongos in vitro y de su localización (Mauch y Staehe- lin, 1989). Obviamente, la función de estas proteínas se asoció en primer lugar, con la de las quitinasas: hidrolizar las paredes de hongos patógenos. Sobre esto hay estudios que indican que cada grupo de enzimas posee una capacidad antifúngica diferente y que ésta, a su vez, varía según la combinación de glucanasas y quitinasas que actúen conjuntamente. Así, la mejor combinación inhibitoria de la germinación de esporas y crecimientos de hongos consiste en una mezcla de las enzimas $\beta$-1,3-glucanasas y quitinasas, ambas de la clase I (Sela- Buurlage et al., 1993).

También se han propuesto modelos que presentan como más eficiente la capacidad inhibitoria del crecimiento fúngico en el conjunto global de la planta. Así, Mauch y Staehelin (1989) llegaron a proponer que la capacidad antifúngica de estas enzimas se debe principalmente a la posibilidad de liberar fragmentos de $\beta$-1,3-glucanos, tanto de la pared de los hongos, como del propio huésped, en el que en situaciones patogénicas se induce la formación de callosidades, que elicitarían la producción de fitoalexinas, y consiguientemente, la respuesta general de la planta. Muchos genes codificadores de productos relacionados con la patogénesis son activados por $\beta$-1,3-glucanos (Ryan, 1987). Aquí se establecería una diferencia en la actuación de las enzimas de la clase I y de la II, de forma tal que las extracelulares (clase II) estarían liberando elicitores, mientras que las vacuolares (clase I) cuyo poder inhibitorio es mayor, serían liberadas al medio a través de la muerte y lisis celular, actuando como segunda barrera de defensa. Se plantea que el crecimiento de los hongos dentro de la planta hospedera se basa en un delicado balance entre la hidrólisis y la síntesis de la pared del ápice de la hifa, en lo que intervendrían las $\beta$-1,3-glucanasas y las quitinasas (Wessels y Siesma, 1981). Si la presencia de una pri- 
mera barrera de enzimas hidrolíticas extracelulares no es efectiva, por no ser adecuado el balance de concentraciones de las enzimas, se establece una primera toma de contacto con el hongo. Una vez que se ha adaptado el hongo al nuevo balance, la liberación masiva y repentina de una serie de enzimas con gran actividad letal, desestabilizaría el balance de enzimas en el ápice de la hifa, produciéndose la muerte del hongo. De esta forma la estrategia de defensa resulta mucho más eficaz.

\section{Proteínas PR-5}

Las proteínas clasificadas en el grupo PR-5 fueron inicialmente identificadas en plantas de tabaco que reaccionaron como hipersensibles ante la infección del Virus del Mosaico del Tabaco (TMV). Son proteínas de bajo peso molecular determinado por un análisis electroforético en gel de poliacrilamida a partir de extractos de hojas de tabaco infestadas por TMV (Kauffmann, 1990).

Solo cuando las proteínas PR-5 fueron secuenciadas, fue que se esclareció la no-relación con la taumatina que es una proteína específica del fruto del Katemfe (Thaumatococcus danielli), que por su sabor dulce y su alta homología con la secuencia aminoácida, estuvo muy relacionada con este grupo, actualmente se plantea que esta proteína no tiene actividad antifúngica (Mandal et al., 1991; Koiwa et al., 1997). Las PR-5 llegaron a conocerse como "Proteínas tipo Taumatina" y bajo esta clasificación se agrupaba también a la osmotina de tabaco y a la NP24 tomate que se acumulan cuando estos cultivos son sometidos a estrés osmótico.

En plantas de tabaco inoculadas con TMV se aisló una proteína de $24 \mathrm{kDa}$, que demostró tener actividad anti-Phytophthora y que fue llamada AP24, esta proteína pura, frecuentemente precipita durante la diálisis en con- diciones de tampón pH 7 necesarios para la actividad biológica. La inhibición sobre $P$. infestans fue una combinación de dos efectos: la lisis del esporangio y la inhibición del crecimiento de la hifa (Woloshuk et al., 1991).

Cuando se comparó la AP24 con la NP24, la fracción que contenía la actividad inhibitoria eluyó en la columna de interacciones hidrofóbicas más temprano que la fracción de proteínas de tabaco. Estos resultados mostraron que tanto la proteína de tomate NP24, como la osmotina de tabaco, inhiben el crecimiento de P. infestans in vitro. La NP24 de tomate resultó ser menos activa que la AP24 de tabaco. La lisis del esporangio se observó a las mismas concentraciones que para la AP24 de tabaco, pero el porcentaje de lisis resultó mucho menor (Wolushuk et al., 1991). La estimación de la masa molecular se diferenció a la reportada para la osmotina (26 $\mathrm{KDa}$ ), sugiriendo que la AP24 es una isoforma diferente de osmotina (Tattersall, 1997).

Se ha visto que la AP24 es acumulada en hojas de tabaco y tomate una vez inducidas por patógenos, sugiriendo que la osmotina no es específica para el estrés osmótico; pero está asociada con un estrés general de respuesta en plantas (Singh et al., 1989). Varias proteínas específicas de semillas de cereales tienen secuencias similares a la de la taumatina sin embargo su acumulación no depende de la presencia de algún patógeno (Malehorn et al., 1994).

La actividad antifúngica del grupo PR-5 ha sido estudiada in vitro, por lo que en la mayoría de los casos, la actividad antifúngica que se le adjudica a las plantas transgénicas es inferida de estos resultados, los que incluyen hasta el momento mas de 10 hongos fitopatógenos además de los incluidos en las clases Oomicetes, Hyphomi- 
cetes y Ascomycetes (Stintzi et al., 1996).

Un grupo de proteínas están relacionadas serológicamente a la osmotina, diferenciándose con respecto a los valores de sus puntos isoeléctricos y su localización extracelular. En ese grupo se incluyen otras proteínas RP-5 de tabaco (Cornelissen et al., 1986; Pierpoint et al., 1987) y de papa (Pierpoint et al., 1990).

Zhu et al. (1996) describieron la modificación de la expresión de un gen de una osmotina en plantas de papa, y dieron una evidencia in vivo del papel biológico de esta proteína en la defensa contra el patógeno $P$. infestans, donde se encontró un retardo en el desarrollo de los síntomas de la enfermedad en plantas transgénicas de papa. La lisis observada sobre la punta del esporangio sugiere que la proteína tiene una actividad de hidrólisis sobre la pared celular. El apéndice del esporangio parece ser un punto débil en $P$. infestans. Otra hipótesis es que la AP24 interactúa con la membrana plasmática debido a su naturaleza hidrofóbica. En apoyo a esta hipótesis está el hecho de que la NP24 de tomate, es menos hidrofóbica y resultó menos activa contra P. infestans (Wolushuk et al., 1991).

Melchers et al. (1993) establecieron: 1.- Que la maduración de AP24 incluye el procesamiento proteolítico de un segmento $\mathrm{N}$ y C-terminal y 2.- Que el propéptido es necesario para el correcto transporte a la vacuola.

Otros investigadores analizaron la expresión en plantas transgénicas de tabaco que contenían diferentes tipos salvajes de AP24, quitinasa y glucanasa básicas, así como genes mutados a los que se les había introducido un codón de parada antes de la región C-terminal y encontraron que, en las plantas transformadas con construcciones de genes truncados, las proteí- nas quiméricas eran exportadas hacia el fluido extracelular, no así en el caso de las plantas sin transformar. También se encontró que la proteína mutante AP24, la cual pierde 20 aminoácidos, migra sobre un gel de SDS-PAGE como la AP24 tipo salvaje. Esto sugiere que después de eliminar el prepéptido señal de la AP24, ocurre un segundo procesamiento, donde es eliminado un fragmento C-terminal de aproximadamente $2 \mathrm{KDa}$. El procesamiento de la proteína AP24 de tabaco incluye la pérdida de un péptido señal de 25 aa y un propéptido C-terminal de 18 aa. La proteína madura AP24 (207 aa) tiene masa molecular calculada de 22336 Da (Melchers et al., 1993).

\section{CONCLUSIONES}

La síntesis de las proteínas PR y su regulación forman parte de las respuestas moleculares que se activan debido a la aparición de patógenos en las plantas resistente. Conocer y entender debidamente los mecanismos moleculares que rigen la síntesis de estas proteínas, permitirá desarrollar métodos destinados a estimular los mecanismos que intervienen en las reacciones de defensa, lo que permitirá tener cultivos mejor protegidos de las plagas y enfermedades, sin tener que aplicar productos químicos contaminantes.

\section{REFERENCIAS BIBLIOGRÁFICAS}

Abeles, B., Bosshart, P., Forrence E. y Habig, H. (1971). Preparation and purification of glucanase and chitinase from bean leaves. Plant Physiol. 47: 129-134.

Antoniw, F., Ritter, E., Pierpoint, S. y Van Loon, C. (1980). Comparison of three pathogenesis-related proteins from plants of two cultivars of tobacco infected with TMV. J. Gen. Virol. 47: 79-87. 
Beerhues, L. y Kombrink, E. (1994). Primary structure and expression of mRNAs encoding basic chitinase and $\beta$-1,3-glucanase in potato. Plant Mol. Biol. 24: 353-367.

Beffa, R. y Meins, F. (1997). Pathogenesis-related functions of plants beta-1,3- Glucanases investigated by antisense transformation. A review. Gene. 179 (1): 97-103.

Bol, F. y Van Kan, L. (1988). The synthesis and possible functions of virus-induced proteins in plants. Microbiol. Sci. 5: 47-52.

Buchel, S. y Linthorst, M. (1999). PR1: A group of plant proteins induced upon pathogen infection. In: Pathogenesis-related proteins in plants. CRC Press.

Carr, P. y Klessig, F. (1989). The pathogenesis-related proteins of plants. En: Setlon J.K. (de) Genetic engineering, principles and methods. Vol. 11. Plenum Press, New York. 65-109.

Castillo, N. (2000). Comunicación personal.

Castresana, C., Carvalho, F., Gheysen, G., Habets, M., Inzé, D. y Van Montagu, M. (1990). Tissue-specific and pathogen-induced regulation of a Nicotiana plumbaginifolia $\beta-1,3$ Glucanase gene. Plant Cell 2: 1131-1143.

Conejero, V. (1981). Stimulation of a viroid-like syndrome and inhibition symptom expression by $\mathrm{Ag}^{+}$ion. $5^{\text {th }}$ Int. Congr.Virol. Strasbourg, France. 228.

Conejero, V. y Granell, A. (1986). Stimulation of a viroid-like syndrome and the impairment of viroid infection in Gynura aurantiaca plants by treatment with silver ions. Physiol. Mol. Plant Pathol. 29: 317-323.
Conejero, V., Ballés, J. M., García-Breijo, F., Garro, R., Hernández-Yago, J., Rodrigo, I. y Vera, P. (1990). Signalling in viroid pathogenesis. En: Fraser RSS (de.) NATO ASI Series, Vol. 14. Recognition and response in plant-virus interactions. Springer-Verlag, Berlin and Heidelberg: 233-261.

Cornelissen, B. J. C., Hooft van Huijsduijnen, R. A. M. y Bol, J. F. (1986). A tobacco mosaic virus-induced tobacco proteins is homologous to the sweet-tasting protein thaumatin. Nature 321: 531-532.

Cote, F., Cutt J., Asselin, A. y Klessig, D. (1991). Pathogenesis-related acidic $\beta-1,3$ glucanase genes of tobacco are regulated by both stress and developmental signals. Mol. Plant Microb Interac. 4: 173-181.

Cutt, J. R. y Klessig, D. F. (1992). pathogenesis-related proteins. En: Boller T. y Meins F.Jr. (eds) Genes involved in plant defense. Springer-Verlag Wien New York. 209-243.

De Jong, A. J., Cordewener, J., Lo Schiavo, F., Terzi, M., Vandekerckhove, V., Van Kammen, A. y De Vries, S. C. (1992). A Carrot somatic embryos mutant is rescued by chitinase. Plant Cell 4: 425-433.

Delp, G. y Palva, E. T. (1999). A novel flower-specific Arabidopsis gene related to both pathogen-induced and developmentally regulated plant $\beta$-1,3-glucanase genes. Plant Mol. Biol. 39 (3): 565-575.

Dixon, R. A. y Lamb, C. J. (1990). Molecular communications in interactions between plants and microbial pathogens. Annu. Rev. Plant Physiol. Plant Mol. Biol. 41: 339-367. 
Ernest, D., Schraudner, C., Langebartels, C. y Sandermann, H. Jr. (1992). Ozone-induced changes of mRNA levels of $\beta-1,3$ glucanase, chitinase and "pathogenesis-related" protein $1 \mathrm{~b}$ in tobacco plants. Plant Mol. Biol. 20: 673-682.

Felix, G. y Meins, F. Jr. (1986). Developmental and hormonal regulation of $\beta-1,3-$ Glucanase in tobaco. Planta 167: 206-211. growing cell wall of angiosperms. Annu. Rev. Plant Physiol. 37: 165-186.

Fulcher, R. G., McCully, M. E., Setterfield, G. y Sutherland, J. (1976). $\beta-1,3-G l u c a n$ may be associated in tomato leaves by citrus exocortis viroid infection are chitinases. Physiol. Mol. Plant Pathol. 36: 249-260.

Gianinazzi, S., Martin, C. y Valle, J. C. (1970). Hypersensibilite aux virus, temperatures et proteines solubles chez Nicotiana Xanthi-nc. Apparition de nouvelles macromolecules lors de la repression de la synthese virale. C.R. Acad. Sci. Paris D. 270: 2382-2386.

Ham, K., Kauffmann, S., Albersheim, P. y Darvill, A. G. (1991). Host- Pathogen Interactions XXXIX. A soybean phatogenesis - related protein with $\beta-1,3$ glucanase activity releases phytoalexin elicitors-active heat-stable fragments from fungal walls. Plant Mol.-Microb. Interac. 4: 545-552.

Hinton, D. M. y Pressey, R. (1980). Glucanase in fruits and vegetables. $\mathrm{J}$. Amer. Soc. Hort. Sci. 105: 1229-1231.

Kauffmann, S. (1990). patogénesis-related proteins of tobacco (Nicotiana tabacum) and other Nicotiana species. Can. J. Bot. 65: 467-481.

Kauffmann, S., Legrand, M., Geoffroy,
P. y Fritig, B. (1987). Biological function of "Pathogenesis-related" proteins: four PR proteins of tobacco have $\beta-1,3$ glucanase activity. EMBO J. 6: 3209-3212.

Keen, N. T. y Yoshikawa, M. (1983). $\beta-1,3$ endoglucanase from soybean release elicitor-active carbohidrates from fungus cell walls. Plant Physiol. 71: 460-465.

Koiwa, H., Kato, H., Nakatsu, T., Oda, J. y Sato, F. (1997). Purification and characterization of tobacco pathogenesis-related protein PR-5d, an antifungal thaumatin-like protein. Plant Cell Physiol. 38 (7): 783-791.

Lamb, C. J., Lawton, M.A., Dron, M. y Dixon, R. A. (1989). Signals and transduction mechanism for activation of plant defense against microbial attack. Cell 56: 215-224.

Legrand, M., Kauffmann, S., Geoffroy, P. y Fritig, B. (1987). Biological function of pathogenesis-related proteins: four tobacco pathogenesis-related proteins are chitinase. Proc. Natl. Acad. Sci. USA 84: 6750-6754.

Leubner-Metzger, G. y Frederick, M. Jr. (1999). Functions and Regulation of plants $\beta$-1,3-glucanases (PR-2) En: Pathogenesis-related proteins in plants. CRC Press.

Leubner-Metzger, G., Petruzzelli, L., Waldvogel, R., Vogeli-Lange, R. y Meins, F. Jr. (1998). Ethylene-responsive element binding protein (EREBP) expression and the transcripcional regulation of class I $\beta-1,3$ glucanase during tobacco seed germination. Plant Mol. Biol. 38 (5): 785-795.

Lotan, T., Ori, N. y Fluhr, R. (1989). Pathogenesis-related proteins are developmentally regu- 
lated in tobacco flowers. Plant Cell 1: 881-887.

Ludwing, A. y Boller, T. (1990). A method for the study of fungal growth inhibition by plants proteins. FEMS Microbiol. Lett. 69: 61-66.

Malehorn, D. E., Borgmeyer, J. R., Smith, C. E. y Shad, D. M. (1994). Characterization and expression of an antifungal Zeamatin-like protein (Zlp) gene from Zea mays. Plant Physiol. 106: 1471-1479.

Mandal, C., Shirley, F., Anchin, J., Mandal, C. y Linthicum, S. (1991). Monoclonal antibodies to sweet taste proteins I. Analysis of antigenic epitopes on thaumatin by competitive inhibition assays. Hybridoma 10 (4): 459-466.

Mauch, F. y Staehelin, L. A. (1989). Functional implications of the subcellular localization of ethylene-induced chitinase and $\beta-1,3$ Glucanase in bean leaves. Plant Cell 1: 447-457.

Mauch, F., Mauch-Mani, B. y Boller, T. (1988). Antifungal hydrolases in pea tissue II. Inhibition offungal groth by combinations of chitinase and $\beta-1,3$ glucanase. Plant Physiol. 88: 936-942.

Mayer, M. G. y Ziegler, E. (1988). An elicitor from Phytophthora megasperma F. Sp. glycinea influences the membrane potential of soybean cotyledonary cells. Physiol. Mol. Plant Pathol. 33: 397-407.

Meier, H., Buchs, L., Buchala, A. J. y Homewood, T. (1981). (1-3) $\beta$-D glucan (callose) is a probable intermediate in biosynthesis of cellulose fibres. Nature 289: 821-822.

Meins, F. Jr., Neuhaus, J. M. Sperisen, C. y Ryals, J. (1992). The primary structure of plant Pathogenesis-Related glucanohydro- lases and their genes. En: Boller, T. y Meins F. (eds.) Genes involved in plant defense. Springer-Verlag, Wien-New York. 245-282.

Melchers, L. S., Sela-Buurlage, M. B., Vloemans, S. A., Woloshuk, C. P., Van Roekel, J. S. C., Pen J., van den Elzen, y Cornelissen, B. J. C. (1993). Extracellular targeting of the vacuolar tobacco proteins AP24, Chitinase and $\beta-1,3$-Glucanase in transgenic plants. Plant Molec. Biolog. 21: 583-593.

Nasser, W., Tapia, M., Kauffmann, S., Montasser-Kouhsair, S. y Burkard, G. (1988). Identification and characterization of maize pathogenesis-related proteins. Four maize PR proteins are chitinase. Plant Mol. Biology 11(4): 529-538.

Neale, A. D., Wahleithner J. A., Lund M., Bonnett H. T., Kelly A., Meeks-Wagner D. R., Peacock W. S. y Dennis E. S. (1990). Chitinase, $\beta-1,3$ Glucanase, osmotin and extensin are expressed in tobacco explants during flower formation. Plant Cell 2: 673- 684.

Ori, N., Sessa, G., Totan, T., Himmelhoch, S. y Fluhr, R. (1990). A major stylar matrix polypeptide (sp41) is a member of the pathogenesis-related proteins superclass. EMBO J. 9: 3429-3436.

Payne, G., Ward, E., Gaffney, T., AhlGoy, P., Moyer, M., Harper, A., Meins, F. Jr. y Ryals, J. (1990). Evidence for a third structural class of $\beta-1,3$ Glucanase in tobacco. Plant Mol. Biol. 15: 797-808.

Pierpoint, W. S., Jackson, P. V. y Evans, R. M. (1990). The presense of thaumatin-like protein, a chitinase and a glucanase among the pathogenesis proteins of potato (Solanum tuberosum). Physiol. Mol. Plant Pathol. 36: 325-338. 
Pierpoint, W. S., Tatham, A. S. y Pappin, D. J. C. (1987). Identification of the virus-induced protein of tobacco leaves that resembles the sweet-tasting protein thaumatin. Physiol. Mol. Plant Pathol. 31: 291-298.

Ryan, C. A. (1987). Oligosaccharides signalling in plants. Annu. Rev. Cell Biol. 3: 295-317.

Ryan, C. A. (1990). Oligosacchasarides as recognition signals for the expression of defensive genes in plants. Biochemistry 27: 8879-8883.

Sela-Buurlage, M. B., Ponstein, A. S., Bres-Vloemans, S. A., Melchers, L.S., van den, Elzen, P. J. M. y Cornelissen, B. J. C. (1993). Only specific tobacco (Nicotiana tabacum) chitinases and $\beta-1,3$ glucanases exhibit antifungal activity. Plant Physiol. 101, 857-863.

Singh, N. K., Nelson, D. E., Kuhn, D., Hasegawa, P. M. y Bressan, R. A. (1989). Molecular Cloning of Osmotin and regulation of this expression by ABA and adaptation to low water potential. Plant Physiol. 90(3): 1096-1101.

Stintzi, A., Heith, T., Prasad, V., Wiedmann-Merdinoglu, E., Kauffmann, S., Geoffroy, P., Legransd, M. y Friti,g B. (1996). Plant "Pathogenesis-related" proteins and their role in defense against pathogens. Biochemie 75, 687-693.

Takeuchi, Y., Yoshikawa, M., Takeba, G., Tanaka, K., Shibata, D. y Orino, O. (1990). Molecular cloning and ethylene induction of mRNA encoding a phytoalexin elicitor- releasing factor $\beta-1,3$ endoglucanase in soybean. Plant Physiol. 93: 673-682.

Van Loon, L. C. (1999). Occurrence and properties of plant pathogenesis- related proteins.
En: Pathogenesis-related proteins in plants. CRC Press.

Van Loon, L. C. y Van Kammen, A. (1970). Polyacrylamide disc electrophoresis of the soluble leaf proteins from Nicotiana tabacum cv. Samsun and Samsun NN. II. Changes in protein constitution after infection with tobacco mosaic virus. Virology 40, 199-211.

Van Loon, L. C., Gerritsen, Y. A. M. y Ritte, R. C. E. (1987). Identification, purification and characterization of pathogenesis-related proteins from virus-infected Samsun NN tobacco leaves. Plant Mol. Biol. 9: 593-609.

Van Loon, L. C., Pierpoint, W. S., Boller, Th. y Conejero, V. (1994). Recomendations for naming plant pathogenesis-related proteins. Plant. Molec. Biol. 12 (3): 245-264

Velazhan, R., Datta, S. y Muthukrishnan, S. (1999). The PR-5 Family: Thaumatin-like proteins. En: Pathogenesis-related proteins in plants. CRC Press.

Vogeli- Lage, R., Frundt, C., Hart, C. M., Beffa, R., Nagy, F. y Meins, F. Jr. (1994). Evidence for a role of $\beta-1,3$ Glucanase in dicot seed germination. Plant J. 5: 273-278.

Vogel, U., Meins, F.Jr. y Boller, T. (1988). Coordinated regulation of Chitinase and $\beta-1,3$ Glucanase in bean leaves. Planta 174: 364-372.

Wessels, J. G. H. y Sietsma, J. H. (1981). Fungal cell walls: a survey. En: W. Tanner y Loewus, eds New Series Vol 13B, Enciclopedia of Plant Physiology. Springer, New York: 352-394.

White, R.F. (1979). Acetylsalicilic acid (aspirin) induces resistance to tobacco mosaic virus in tobacco. Virology 99, 410-412. 